\title{
Dicentric chromosome in the bone marrow of a child with megakaryoblastic leukaemia and Down's syndrome
}

\author{
A O M WILKIE, * ClARE KITCHEN, $\dagger$ A OAKHILL, * R T HOWELL, $\dagger$ P J BERRY
}

From the Departments of *Paediatric Oncology and $\ddagger$ Paediatric Pathology, Bristol Children’s Hospital, Bristol; and the $†$ South West Regional Cytogenetics Centre, Southmead Hospital, Bristol

SUMMARY A two year old girl with Down's syndrome (constitutional karyotype: $47+21$ ), presenting with pancytopenia, developed acute megakaryoblastic leukaemia (AMKL). Her bone marrow contained an abnormal clone with a novel dicentric chromosome derived from chromosomes 5 and 7 (karyotype 46, XX, $-5,-7,+\operatorname{dic}(5 ; 7)(\mathrm{p} \mathrm{13;p} \mathrm{11 \cdot 2),} \mathrm{+21.} \mathrm{This} \mathrm{case} \mathrm{provides} \mathrm{further}$ evidence for a connection between chromosome 21 and this unusual form of childhood leukaemia, and raises questions about the loss of short arm material from chromosomes 5 and 7 compared with the more usual monosomy or long arm loss.

\section{Case report}

A two year old caucasian girl with Down's syndrome presented with a three week history of anorexia, lethargy, and bleeding from the gums. There were no relevant abnormalities on physical examination apart from pallor and bruising. The initial blood count was haemoglobin $4 \cdot 1 \mathrm{~g} / \mathrm{dl}$, white cells $3.31 \times 10^{9} / 1$ (neutrophils $0.86 \times 10^{9} / 1$, lymphocytes $2.28 \times 10^{9} / 1$, monocytes $0.17 \times 10^{9} / 1$, no blast cells), and platelets $17 \times$ $10^{9} / 1$. A bone marrow aspirate and trephine biopsy specimen showed hypocellularity and pronounced fibrosis with scanty blast cells present. These cells were negative for the lymphoblast markers CD10, DR, and TdT, and had the appearance of megakaryoblasts. Initial treatment was supportive, with red cell and platelet transfusions and antibiotics. A repeat bone marrow trephine biopsy specimen taken one month later showed increased cellularity and included numerous cells with characteristic megakaryoblastic morphology. These cells stained positively with monoclonal antibodies to platelet glycoproteins IB and IIB/ IIIA. Acute megakaryoblastic leukaemia (AMKL) was diagnosed. She was treated with daunorubicin, cytosine arabinoside, etoposide, cyclophosphamide, thioguanine and intrathecal methotrexate, and 13 months after diagnosis was in remission.

Accepted for publication 5 October 1987

\section{Cytogenetic studies}

The constitutional karyotype ascertained from stimulated lymphocyte cultures was $47+21$. Trypsin $G$ banding analysis of metaphases from the initial bone marrow aspirate showed a clonal karyotype with a dicentric chromosome resulting from a translocation between the short arm of one chromosome 5 and the short arm of one chromosome 7 (figure). The clonal karyotype was interpreted as $46, \mathrm{XX},-5,-7$, + dic $(5 ; 7)$ ( p 13; p 11.2), +21. Lymphocyte cultures stimulated by phytohaemagglutinin and exposed to mitomycin $\mathrm{C}$ or mustine hydrochloride had chromosome aberrations in the normal range of

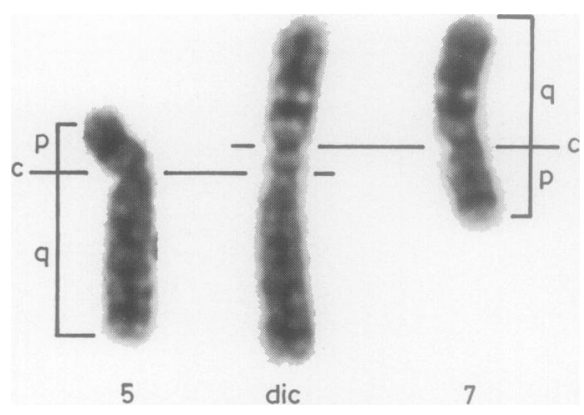

Figure Abnormal dicentric chromosome (dic) shown paired with normal homologues of chromosomes 5 and 7: p-short arm; q-long arm; c-centromere positions. 
frequency, thus excluding Fanconi's anaemia. Examination of polymorphic variation in the short arms of chromosomes 21 by $\mathrm{G}$ and $\mathrm{Q}$ banding was unremarkable.

\section{Discussion}

AMKL (FAB classification, M7 $^{1}$ ) was, until recently, considered to be a rare form of acute non-lymphocytic leukaemia (ANLL), characterised by the abnormal proliferation of megakaryoblasts. ${ }^{2}$ The development of methods for immunological identification of blast cells should, however, increase its recognition. In two recent reports ${ }^{34}$ AMKL represented $8 \%$ of all leukaemia cases, unselected for age, when antibodies to platelet glycoprotein IIB/IIIA complex and factor VIII/von Willebrand factor complex were used to characterise the cells of megakaryocyte/platelet lineage. It seems likely that many of the previously reported cases of childhood acute myelofibrosis ${ }^{5}$ will now be classified as AMKL.

The clinical findings in 20 cases of AMKL in children have been summarised ${ }^{2}$; to these may be added eight more cases, ${ }^{4-10}$ and there is also a recent report of Fanconi's anaemia associated with AMKL." Down's syndrome was present in five of the above cases $^{28}{ }^{10}$; all of these developed AMKL before the age of 4 years. Another patient had a constitutional ring 21 chromosome but was phenotypically normal. ${ }^{12}$ Together with the present report there are 18 childhood cases of AMKL in which karyotype analysis of bone marrow has been performed, including three of the patients with Down's syndrome. ${ }^{28}$ Multiple acquired chromosomal anomalies were found in 15 cases; the most common change was an extra chromosome 21 , detected in six of the patients with a constitutionally normal karyotype. ${ }^{2679}$ ?

Down's syndrome is well known to be over represented in the leukaemic population, occurring in $2-5 \%$ of unselected leukaemic children and possibly in up to $15 \%$ of those presenting with ANLL before the age of 2 years. ${ }^{13}$ The proportion of children with AMKL who have Down's syndrome is higher than in other forms of ANLL (six of 30). An association between childhood acute myelofibrosis and Down's syndrome has also been described. ${ }^{5}$ The occurrence of an additional chromosome 21 in the leukaemic cells of six of 15 of the other cases of AMKL is also particularly common, even though an additional chromosome 21 is a common acquired karyotypic change in acute leukaemia, both in normal children, ${ }^{14}$ and in those with Down's syndrome. ${ }^{15}$ Together, these findings provide evidence for a closer association between AMKL and the presence of additional copies of chromosome 21 than occurs in other forms of leukaemia, although bias due to the small number of cases cannot be excluded.

The occurrence of the dic $(5 ; 7)$ in the case reported here is of interest for two reasons. Firstly, dicentrics affecting two non-homologous chromosomes are relatively uncommon in leukaemia, ${ }^{16}$ probably because they are inherently unstable. Secondly, the leukaemic clone was effectively monosomic for most of the short arms of chromosomes 5 and 7. Although loss of material from these two chromosomes is a well recognised phenomenon in ANLL and myelofibrosis, especially when related to. previous cytotoxic treatment or radiotherapy, ${ }^{17-19}$ this loss almost always affects either the long arms alone $(5 q-, 7 q-)$ or the whole chromosome (monosomy 5,7 ). In only two previous reports of AMKL have similar abnormalities been described, one with monosomy $7,{ }^{2}$ the other with monosomy $7 p$ resulting from the formation of an isochromosome $7 \mathrm{q}^{8}$

The cause of the association between Down's syndrome and ANLL in early childhood remains a mystery. As the relative risk compared with that of the normal population falls progressively with age,$^{13}$ the predisposition to ANLL may be associated with only a small subgroup of patients with Down's syndrome. The observation of transient leukaemoid reactions in some infants with Down's syndrome and the association with the trisomy 21 cells in mosaics ${ }^{20}$ suggest that the extra chromosome 21 may be a primary trigger for the oncogenic process. Those mosaics which arise from a post-zygotic mitotic error, are homozygous for two of their chromosomes 21 in the trisomic cells: it would be interesting to determine whether homozygosity for a critical part of chromosome 21 is the rule in children with Down's syndrome who develop ANLL.

\section{References}

1 Bennett JM, Catovsky D, Daniel M-T, et al. Criteria for the diagnosis of acute leukaemia of megakaryocyte lineage (M7). A report of the French-American-British Cooperative Group. Ann Int Med 1985;103:460-2.

2 Cairney AEL, McKenna R, Arthur DC, Nesbit ME, Woods WG. Acute megakaryoblastic leukaemia in children. $\mathrm{Br} J$ Haematol 1986;63:541-54.

3 Huang MJ, Li CY, Nichols WL, Young JH, Katzman JA. Acute leukemia with megakaryocytic differentiation: a study of 12 cases identified immunocytochemically. Blood 1984;64:427-39.

4 Ruiz-Arguelles GJ, Marin-Lopez A, Lobato-Mendizabal E, RuizArguelles A, Nichols WL, Katzman JA. Acute megakaryoblastic leukaemia: a prospective study of its identification and treatment. Br J Haematol 1986;62:55-63.

5 Evans DIK. Acute myelofibrosis in children with Down's syndrome. Arch Dis Child 1975;50:458-62.

6 Hanada T, Nakazawa M, Sakuma H, Takahashi M, Kondo I, Takita H. Megakaryoblastic transformation of chronic myelogenous leukaemia in a child. Scand $J$ Haematol 1984;33:476-81.

7 Pui C-H, Rivera G, Mirro J, Stass S, Peiper S, Murphy SB. Acute megakaryoblastic leukemia. Blast cell aggregates simulating metastatic tumor. Arch Pathol Lab Med 1985;109:1033-5. 
8 Suarez CR, Le Beau MM, Silberman S, Fresco R, Rowley JD. Acute megakaryoblastic leukemia in Down's syndrome: report of a case and review of cytogenetic findings. Med Pediatr Oncol 1985;13:225-31.

9 Witte DP, Harris RE, Jenski LJ, Lampkin BC. Megakaryoblastic leukemia in an infant. Establishment of a megakaryocytic tumor cell line in athymic nude mice. Cancer 1986;58:238-44.

10 Suda T, Suda J, Miura Y, et al. Clonal analysis of basophil differentiation in bone marrow cultures from a Down's syndrome patient with megakaryoblastic leukemia. Blood 1985;66:1278-83.

11 Dharmasena F, Catchpole M, Erber W, Mason D, Gordon-Smith EC. Megakaryoblastic leukaemia and myelofibrosis complicating Fanconi anaemia. Scand J Haematol 1986;36:309-13.

12 Pui C-H, Williams DL, Scarborough V, Jackson CW, Price R, Murphy S. Acute megakaryoblastic leukaemia associated with intrinsic platelet dysfunction and constitutional ring 21 chromosome in a young boy. Br J Haematol 1982;50:191-200.

13 Stiller CA, Kinnier Wilson LM. Down syndrome and leukaemia. Lancet 1981 ;ii: 1343.

14 Rowley JD. Down syndrome and acute leukaemia: increased risk may be due to trisomy 21 . Lancet 1981;ii:1020-2.

15 Hecht F, Hecht BK, Morgan R, Sandberg AA, Link MP. Chromosome clues to acute leukemia in Down's syndrome. Cancer Genet Cytogenet 1986;21:93-8.
16 Mitelman F. Catalog of chromosome aberrations in cancer. 2nd Ed. New York: Alan R Liss, 1985.

17 Le Beau MM, Albain KS, Larson RA, et al. Clinical and cytogenetic correlations in 63 patients with therapy-related myelodysplastic syndromes and acute nonlymphocytic leukemia: further evidence for characteristic abnormalities of chromosomes No. 5 and 7. J Clin Oncol 1986;4:325-45.

18 Fourth International Workshop on Chromosomes in Leukemia, 1982. Deletion of 5q. Cancer Genet Cytogenet 1984;11:296-9.

19 Fourth International Workshop on Chromosomes in Leukemia, 1982. Abnormalities of chromosome 7 resulting in monosomy 7 or in deletion of the long arm $(7 q-)$ : review of translocations, breakpoints, and associated abnormalities. Cancer Genet Cytogenet 1984;11:300-3.

20 Ferster A, Verhest A, Vamos E, De Maertelaere E, Otten J. Leukemia in a trisomy 21 mosaic: specific involvement of the trisomic cells. Cancer Genet Cytogenet 1986;20:109-13.

Requests for reprints to: Dr A Oakhill, Department of Paediatric Oncology, Bristol Children's Hospital, St Michael's Hill, Bristol BS2 8BJ, Avon, England. 